\title{
TRABALHO, EDUCAÇÃO E AMBIENTE EM PLENO NEODESENVOLVIMENTISMO: TECENDO CONCEITOS E CONTRADIÇÕES
}

\author{
Thiago da Silva Oliveira*, Alexandre Maia do Bomfim \\ *E-mail: thiagosilvaoliveira1989@gmail.com \\ Instituto Federal de Educação Ciência e Tecnologia do Rio de Janeiro
}

DOI: $10.15628 /$ rbept.2020.11609

Artigo submetido em: set/2020 e aceito em: dez/2020

\begin{abstract}
RESUMO
Este artigo segue no caminho de constituir uma Educação Ambiental Crítica, assentada nos referencias teóricos da área de Trabalho-Educação, no contexto do neodesenvolvimentismo. Nosso pressuposto é que aspectos do projeto neodesenvolvimentista se distanciam do desenvolvimentismo clássico porque são incorporadas novas pautas e outras são dispensadas, como a inclusão da preocupação com o meio ambiente com a relativização da industrialização. Neste percurso encontramos contradições como o estímulo ao consumismo, proporcionado pela política de inclusão via consumo de massas, associado a uma educação ambiental preocupada apenas com o final do processo de produção das mercadorias. No fim, este trabalho contribui para o fomento de uma educação endereçada a transformar a realidade socioambiental e crítica do sistema do capital.
\end{abstract}

Palavras-chave: Educação Ambiental Crítica. Desenvolvimentismo e Ambiente. Neodesenvolvimentismo e Ambiente. Trabalho-Educação e Ambiente. Educação e Neodesenvolvimentismo.

\section{LABOR, EDUCATION AND ENVIRONMENT IN THE NEODEVELOPMENTALISM: CONCEPTS AND CONTRADICTIONS}

\begin{abstract}
This article follows the path of constituting a Critical Environmental Education, based on the theoretical references of the Labor-Education area, now in the context of Neodevelopmentism. Our assumption is that aspects of the Neodevelopment project are distant from classic developmentalism because new guidelines are incorporated and others are dispensed with, such as the inclusion of concern for the environment with the relativization of industrialization. In this path, we find contradictions such as the stimulus to consumerism, provided by the inclusion policy via mass consumption, associated with an environmental education concerned only with the end of the goods production process. In the end, this work contributes to the promotion of an education interested in transforming the socioenvironmental and critical reality of the capital system.
\end{abstract}

Keywords: Critical Environmental Education. Developmentalism and Environment. Neo development and Environment. Labor-Education and Environment. Education and Neo developmentism. 


\section{INTRODUÇÃO}

O presente artigo faz parte de uma pesquisa maior ${ }^{1}$ que se preocupou em problematizar a Educação Ambiental (EA) no contexto neodesenvolvimentista, encontrado em período recente no Brasil. Essa problemática surgiu do interesse de fazer contraponto a uma EA limitada à estrutura do desenvolvimento capitalista.

Nosso primeiro desafio foi perceber que mesmo as perspectivas mais progressistas da sociedade não conseguem propor algo estruturalmente alternativo. Como, por exemplo, em relação ao consumismo estrutural, estimulado desde sempre. Vale um discurso do então presidente Luís Inácio da Silva (Lula), de 2008 que trata dessa questão.

[O trabalhador] pensa assim: eu não vou fazer a compra porque eu tenho medo de perder o emprego. O que eu quero dizer é que ele corre o risco de perder o emprego se ele não comprar, porque ele não comprando o comércio não encomenda para indústria, que não produz, e sem produzir, não tem emprego [na indústria]. [Presidente Luís Inácio Lula da Silva em 2008, sobre a crise que abateu a economia mundial no final da primeira década do sec. XXI] (apud BOMFIM, 2010, p.11).

Essa passagem revela a estrutura inegociável do sistema, onde o estímulo ao consumo é indispensável para o funcionamento da economia, dessa forma podemos considerá-lo um "defeito estrutural" (MÉSZÁROS, 2008).

Dessa forma, este artigo tem dois objetivos principais: (1) desvelar até que ponto pode ir o projeto do neodesenvolvimentismo com a pauta ambiental, considerando que o projeto de "inclusão via consumo de massas" não se esgotou completamente, como afirma Dowbor (2017); e, (2) realizar uma breve análise de conjuntura de um período histórico recente do Brasil em relação à questão ambiental.

$\mathrm{O}$ artigo está organizado em três partes. Na primeira constituímos o que seria uma EA-Crítica, nossa filiação. A seguir, nos dedicaremos a refletir sobre o desenvolvimentismo clássico latino-americano e o recente neodesenvolvimentismo. Por fim, discutiremos os interesses teóricos e práticos desse neodesenvolvimentismo à questão ambiental.

\footnotetext{
${ }^{1}$ De acordo com Oliveira (2019).
}

Vol. 02 (2020) 


\section{A BASE PARA UMA EDUCAÇÃO AMBIENTAL CRÍTICA}

O ser humano como ser histórico vale-se do trabalho para transformar a natureza e a si mesmo, assim, o trabalho se apresenta como pré-condição histórica do desenvolvimento social e como mediador entre o homem e suas necessidades. Apesar disso, a realidade em que vivemos manifesta a percepção negativa do trabalho, sua forma como tripalium, ou seja, como uma atividade dolorosa, alienada. Nessa realidade o fruto do trabalho não pertence ao trabalhador, mas ao capitalista, que retira o seu lucro dessa relação de exploração.

Decorrente dessa exploração, o modo de produção capitalista se estrutura em contradições, como: a necessidade de explorar o trabalho no mesmo momento em que tenta camuflar isso; explorar o trabalhador procurando evitar seu comando ou mesmo seu esgotamento; o desenvolvimento em bases econômicas e sociais desiguais, ao passo que enuncia a igualdade perante a lei. Ou seja, o capitalismo acaba sendo semelhante às sociedades que o antecederam, possui um sistema econômico que tenta explorar ao máximo o elemento que lhe dá sustentabilidade e acaba mantendo a divisão de classes. Bomfim (2014) adverte que foi através desse modo de produção que construímos uma sociedade consumidora, desigual e bélica.

Assim como o trabalho é submetido à lógica do lucro, a natureza segue o mesmo caminho ${ }^{2}$, sendo mercantilizada e explorada para a reprodução do "sistema do capital" (como prefere dizer MÉSZÁROS, 2002). Isso significa que, embora não constitua uma segunda contradição ${ }^{3}$ para o capital, a degradação da natureza se assemelha à degradação do trabalhador.

Vai ficando cada vez mais claro para educadores ambientais críticos que dentro do capitalismo a questão ambiental só obterá respostas

\footnotetext{
${ }^{2}$ Foster (2011) indica que o capitalismo se inicia como um sistema de usurpação da natureza e da riqueza pública, uma vez que a separação entre os trabalhadores e a terra é precondição histórica para o desenvolvimento desse modo de produção e para a emergência do proletariado.

3 Embora a origem da degradação ambiental coincida com a exploração do trabalho, não se pode afirmar que haja uma contradição imediata entre o capitalismo e a exploração da natureza, uma vez que a destruição do ambiente natural não poria em perigo as condições de reprodução do capitalismo (CHESNAIS e SERFATI, 2003). Pelo contrário, a escassez pode proporcionar bons e novos negócios ao Sistema do Capital, "Quanto mais a natureza se exaurir, mas se vislumbra a possibilidade de mercantilizar a água, o ar, a beleza, o que restar do verde, dos animais etc." (BOMFIM, 2011, p.14)
} 
paliativas ${ }^{4}$. Lima (2003) aponta, por exemplo, que no contexto das políticas neoliberais postas em práticas a partir dos anos 80 houve uma hegemonia do projeto declarado como Desenvolvimento Sustentável (DS). O estilo conciliador do DS buscou promover um consenso entre as diversas concepções e grupos divergentes, tentando suavizar ou camuflar os conflitos que os dividiam. "Esse campo permitiu aproximar [...] conservacionistas e ecologistas, empresários e ambientalistas, ongs, movimentos sociais e agências governamentais" (LIMA, 2003, p.104). O problema é que com o passar dos anos esse projeto político vem se mostrando de pouquíssima eficácia.

Uma das principais construções do DS foi a afirmação de um "mercado verde", que convoca a consciência dos indivíduos e a responsabilidade das empresas para um "consumo consciente". Daí seguem as propostas de crédito de carbono, selos verdes, eco-tecnologias, entre outras. Essas respostas apresentam duas características importantes para a reflexão dos educadores ambientais: a primeira é que se transfere a crítica geral do modo de produção capitalista para a elucubrações específicas sobre o consumo, ou seja, não se critica a estrutura do sistema; em sintonia com essa característica, essas medidas promovem o crescimento dos negócios e dinamiza a economia, o que logicamente tende a hegemonizar-se na sociedade de mercado.

Uma prática pedagógica nos limites desses pressupostos aposta na mudança do comportamento dos indivíduos como o caminho para uma sociedade sustentável. Um caminho que se restringe a ensinar os indivíduos a reverem seus comportamentos: consumir os produtos certos, da forma certa; separar, reutilizar e reciclar o lixo corretamente; diminuir o tempo no banho; etc. Ou seja, a EA passa a desempenhar um papel puramente dogmático, em que as atitudes dos sujeitos se tornam irrefletidas e, portanto, facilmente manipuláveis por políticas ineficazes, assim como por estratégias de marketing.

Por buscar alternativas dentro da lógica do sistema capitalista, essa Educação Ambiental Conservadora (EA-conservadora), não-crítica, tem suas possibilidades de transformação social limitada. O que torna indispensável ao educador ambiental, realmente interessado na transformação da sociedade, refletir "para além do capital" (MÉSZÁROS, 2002), procurando distinguir quem mais sofre com as mazelas ambientais em relação a quem mais exaure o planeta com seu nível de consumo excessivo ou exploração; quem não

4 É importante destacar que estamos aqui nos contrapondo a dois grupos de pensadores ambientais: (1) aqueles que se expressam por meio das correntes conservacionistas e apontam a mudança comportamental dos indivíduos como o alicerce da sustentabilidade; e (2) os que tentam conciliar de forma pragmática a defesa do meio ambiente ao desenvolvimento econômico, advogando pelo consumo sustentável e se apoiando nas tecnologias "verdes". Para aprofundamento sobre essas vertentes consultar Lima; Layrargues (2011). 
tem a possibilidade de fugir dos ambientes poluídos em relação aos que poluem excessivamente etc. (BOMFIM, 2010). É necessário reaver historicamente a sociedade de classes.

Autores, como Bomfim (2010), Guimarães (2012), Lima e Layrargues (2011), entre outros, propõem a crítica dessa Educação Ambiental, sustentada em uma leitura mais complexa e orgânica para a transformação da realidade socioambiental. Algo bem diferente de uma Educação Ambiental Conservadora, cujas orientações se voltariam à manutenção do status quo (portanto, ineficiente e ineficaz em realizar seus propósitos).

Nessa abordagem, contra-hegemônica, pretende-se, entre outras coisas, distinguir os diferentes discursos ideológicos presentes no ato educacional. Em outros termos, para alcançar uma Educação Ambiental Crítica (EA-Crítica), não se pode ignorar os antagonismos de classes, devese entender que uma das principais características de uma sociedade desigual é o conflito de interesses e pressupor a inevitabilidade do confronto político.

Outro ponto fundamental para a Educação Ambiental se fazer crítica é a problematização do consumismo estrutural ${ }^{5}$, já que coloca em evidência a insustentabilidade do modo de produção da sociedade capitalista (o consumo possibilita o aumento constante da produção). Lowy (2009) comentando sobre o consumismo numa sociedade democraticamente planejada, argumenta que o fetichismo dos bens de consumo ${ }^{6}$ provoca necessidades artificiais e defende que o critério, para distinguir se uma necessidade é autêntica ou artificial, seria a sua permanência após a supressão da publicidade (LOWY, 2013).

Por isso seria necessário lidar de uma outra forma com o consumo (inevitável) e iniciar um novo modo de viver, onde o centro da organização

5 Chamamos de "consumismo estrutural" a força que adquire o consumo como discurso e
como prática econômica percebida no contexto da reestruturação capitalista, do fordismo
para a produção flexível (cf. Harvey, 2017). Nessa reestruturação sistêmica, a produção em
massa deixa de ser relevante e a produção se volta à satisfação imediata da demanda,
reduzindo o desperdício e valorizando o consumo como promotor do desenvolvimento
econômico. No Brasil, o governo do Partido dos Trabalhadores (PT) se notabilizou pelas
políticas em favor do consumo, como a expansão do crédito e a transferência de renda
direta, com vista ao crescimento econômico. Logo, pode-se dizer que existe um consumismo
estrutural brasileiro. Acrescente-se que não sendo o escopo deste artigo ficarão algumas
ideias pendentes, como por exemplo a necessidade de relativização desse conceito de
"consumismo estrutural", porque embora o capitalismo não possa prescindir dele, pode não o
garantir para todos, porque o consumismo estrutural pode se ligar perfeitamente a uma alta
desigualdade social.

${ }^{6}$ Conceito apontado pela teoria do valor de Marx, através da separação entre valor de uso (inerente à mercadoria) e valor de troca (manifestado no ato de troca entre duas mercadorias), onde o valor de uso é minimizado em favor do valor de troca e as relações humanas complexas passam a ser externadas apenas como uma relação entre coisas. Tendo a sociedade capitalista suas bases firmadas na produção de mercadorias, é mister que o homem deixa de ser o centro do desenvolvimento e a sua própria produção o domina. 
social esteja na satisfação da diversidade de nossas necessidades e aspirações humanas e não somente naquelas produzidas artificialmente pela publicidade; necessidades que não sejam orientadas ao acúmulo e que possam ser revistas quando forem atendidas de forma desigual. Assim como há valorização do valor de troca em detrimento do valor de uso, com estratégias como a obsolescência planejada e a inovação estética por que não impulsionar o ser humano para outros lugares, outras possibilidades? A proposta de Lowy vai na direção de uma educação engajada pela transformação do sistema do capital, o que desejamos para a EA-Crítica.

Por fim, percebe-se que em vez de uma lista de regras comportamentais, a EA-Crítica se dispõe a retirar as certezas sobre cujas bases estão assentadas a sociedade de classes, tendo isso em vista a contextualização da realidade na qual vivemos se torna uma premissa básica para realizar a crítica. Essas reflexões são necessárias, uma vez que desmontam as práticas irrefletidas e germinam novas formas de fazer uma educação realmente transformadora. No limite, a EA-Crítica não somente é uma alternativa às práticas educacionais, mas é, sobretudo, uma possibilidade real de mudança em direção à uma sociedade sustentável.

\section{O DESENVOLVIMENTISMO LATINOAMERICANO}

A década de 1950 marca na América Latina o início de uma série de interpretações independentes sobre a situação socioeconômica da região. essas análises buscavam, sobretudo, o esclarecimento de certas observações empíricas que contradiziam a teoria econômica ortodoxa. Um grande alvo dessas interpretações foi a chamada "Lei das Vantagens Comparativas", que apregoava uma justa distribuição dos benefícios do progresso técnico dos países industrializados a todos os grupos da sociedade, o que criaria uma situação cômoda para os produtores de bens primários (PREBISCH, 1962).

Nesta compreensão os países deveriam se concentrar em produtos favoráveis aos seus contextos geográficos, para, a partir da troca internacional, se beneficiarem do contínuo progresso tecnológico industrial. Isso significa que o papel dos países de produção primária na Divisão Internacional do Trabalho (DIT) seria o de manterem essas produções, assim o mercado garantiria o equilíbrio necessário para todos saírem ganhando. Ademais, os países produtores de bens primários não deveriam se arriscar em investir na industrialização, "ao contrário, sua menor eficiência os faria perderem irremediavelmente os benefícios clássicos do intercâmbio" (PREBISCH, 1962, p.72).

Um exemplo comumente citado da desconfiança latino-americana a 
essa ideia é o texto clássico de abertura do primeiro Estudo Econômico da América Latina, desenvolvido pela Comissão Econômica para a América Latina (CEPAL), escrito em 1949 por Raul Prebisch, fundador e ex. diretor do Banco Central da Argentina. Nesse trabalho, Prebisch questiona os argumentos da ortodoxia liberal, que, segundo ele, seriam desmentidos constantemente pelos fatos.

Em suas palavras,

Existe [..] um desequilíbrio patente e, seja qual for sua explicação ou a maneira de justificá-lo, ele é um fato indubitável, que destrói a premissa básica do esquema da divisão internacional do trabalho. (PREBISCH, 1962, p.73)

E reitera que é,

Fundamental a industrialização dos novos países. Ela não constitui um fim em si, mas é o único meio de que estes dispõem para ir captando uma parte do fruto do progresso técnico e elevando progressivamente o padrão de vida das massas. (PREBISCH, 1962, p.74)

A industrialização se apresentava nesse contexto como o motor para alcançar o desenvolvimento. Essa perspectiva se hegemonizou a partir das interpretações cepalinas sobre os desequilíbrios entre os países industrializados e os não-industrializados. Termos como "deterioração dos termos de troca", "centro e periferia", "subdesenvolvimento", "desenvolvimento retardado", "dependência", entre outros, se tornaram cotidianos no pensamento político-econômico latino-americano e, mais especificamente, brasileiro.

Apesar da heterogeneidade entre os países, as análises feitas pela Cepal encontraram dificuldades em comum entre os países da América Latina, como: falta de infraestrutura logística, energética e automobilística; baixa eficiência dos setores de comunicação; setor agrário ineficiente e concentrador de terras; e, principalmente, a ausência de acumulação do capital apropriado para financiar a industrialização (HAFFNER, 2002). Para resolver esses problemas seria necessária a intervenção direta do estado na economia, protegendo produtos nacionais, investindo em infraestrutura e na criação de empresas estatais para atuar em produtos considerados estratégicos, estimulando empresas nacionais e estrangeiras a investir no país etc. Em suma, o estado deveria planejar e organizar o desenvolvimento na busca de substituir bens importados por produtos nacionais.

Além disso, Bresser-Pereira ${ }^{7}$ (2005) observa, que os intelectuais da

\footnotetext{
7 O autor analisa os avanços teóricos do Instituto Superior de Estudos Brasileiros ISEB e da CEPAL na década de 50 sobre a teoria da dependência. Como o contexto pós-depressão de 29 e segunda guerra mundial é favorável às ideias de intervenção estatal ambos os núcleos de estudos seguem a linha de fortalecimento interno das nações num projeto amplo e unificado das burguesias nacionais e dos técnicos do estado.
} 
CEPAL não consideravam o atraso decorrente da colonização o único fator do subdesenvolvimento da região, mas, incluíam nessa equação o interesse dos países do centro imperial em manter a região produzindo matérias-primas. Superar essa realidade exigia um pacto nacionalista entre os trabalhadores e as burguesias nacionais, por este motivo o desenvolvimentismo, nos países em que foram postas em prática as considerações cepalinas, ficou conhecido como "Nacional-desenvolvimentismo".

O desenvolvimento nacional se daria através de um esforço voluntário dos agentes internos na busca de se contrapor aos interesses internacionais, não só ideológicos, mas, em alguns casos, financeiros também ${ }^{8}$. Nesse ínterim, o nacionalismo se torna a conexão que faz o desenvolvimentismo se estabelecer como estratégia, por isso sua relevância é incontestável.

Essas três características principais (a defesa da industrialização, o intervencionismo econômico pró-crescimento e o nacionalismo) foram consideradas o núcleo duro do pensamento desenvolvimentista (FONSECA, 2004; PAULANI, 2012; BRESSER-PEREIRA, 2013), a identidade desse projeto. Pode-se perceber essas características tanto nos governos de Getúlio Vargas, quanto nos de Juscelino Kubitschek e mesmo durante a ditadura civil-militar, embora cada um destes tenha tido suas diferenças peculiares que não serão tratadas neste trabalho.

\subsection{NEODESENVOLVIMENTISMO: A POLÊMICA DO TERMO E A POSSIBILIDADE DE SUAATUALIZAÇÃO}

A eleição do Partido dos trabalhadores (PT) ao comando do poder executivo em 2002 recolocou o debate sobre o desenvolvimentismo no cotidiano político e acadêmico brasileiro, agora com a denominação de "novodesenvolvimentismo". A já clássica "Carta ao Povo Brasileiro", assinada por Lula em 2002, revelou as expectativas do governo Lula em "abrir o caminho de combinar o incremento da atividade econômica com políticas sociais consistentes e criativas"9.

Para Bresser-Pereira (2013), o êxito de uma política desenvolvimentista depende de uma coalizão de classes envolvendo

8 O Nacional-desenvolvimentismo de Getúlio Vargas, apresentou um ceticismo quanto ao investimento de capitais estrangeiros na economia brasileira. Acima de tudo no que se referia a setores estratégicos, como o do petróleo, da mineração, do transporte e da energia elétrica, assim como da indústria siderúrgica e química, esses setores eram defendidos como estatais e garantiam a soberania nacional. Os demais setores poderiam ser privatizados desde que seguisse um planejamento econômico de caráter nacional. (cf. HAFFNER, 2002).

9 Disponível em: http://www1.folha.uol.com.br/folha/brasil/ult96u33908.shtml. Acesso em: 16 fev. 2019. Acesso em: 25 nov. 2020.

Vol. $02(2020)$ 
empresários industriais, trabalhadores e burocracia pública. Em função disso, - autor destaca esse "novo pacto nacional", presente na política de conciliação de classes do governo Lula, como o caminho para políticas notadamente desenvolvimentista, embora não necessariamente bem sucedidas.

Outro ponto importante para entendermos o período petista vem da tese de doutoramento de Aloizio Mercadante Oliva, um participante do próprio governo. Mercadante (2010) afirma que chama de novo-desenvolvimentismo a práxis de um governo popular que contrariou a agenda neoliberal e deflagrou um novo processo econômico, social e político e não um planejamento estratégico estruturado em metodologias ou teorias econômicas.

Se de fato não havia um pensamento estruturado chamado novodesenvolvimentismo é certo que os programas sociais de distribuição de renda e valorização do salário-mínimo, ampliação de crédito e investimentos em infraestrutura do período Lula, preparou o terreno para uma abrangente discussão sobre uma nova proposta econômica de desenvolvimento ${ }^{10}$. Diversos autores passaram a reivindicar o novo-desenvolvimentismo como objeto de estudos e, a partir daí, formularam teorias concorrentes que buscam, ainda hoje, a hegemonia conceitual deste termo.

Diante da quantidade de pesquisas realizadas sobre o tema, Paulani (2017) aponta que a consistência teórica dos novo-desenvolvimentistas acabou culminando, a partir do primeiro mandato de Dilma Rousseff, no afastamento de duas tendências majoritárias: os novo-desenvolvimentistas, liderados por Bresser-Pereira, mais preocupados com os aspectos macroeconômicos (BASTOS, 2012); e, os Social-desenvolvimentistas, tendo o Instituto de Economia da UNICAMP como a principal fonte dos seus fundamentos, preocupados em convergir o crescimento com equidade social (SICSÚ; PAULA; MICHEL, 2007).

Esse debate ganha contornos ainda mais polêmicos com a posição de pesquisadores que negam a relação desse processo econômico com o projeto nacional-desenvolvimentista do século $\mathrm{XX}$, a partir deste momento o próprio termo "desenvolvimentismo" começa a ser questionado. Paulani (2017), por exemplo, problematiza a possibilidade de um desenvolvimentismo na estrutura do capitalismo financeirizado - exibido no governo petista; assim como vê certa dificuldade em atribuir aos teóricos do neodesenvolvimentismo ${ }^{11}$ a característica de desenvolvimentistas, uma vez

\footnotetext{
10 Pilares que permitiram, nas palavras de Laura Carvalho (2018), um "milagrinho" socioeconômico no Brasil, um passo à frente na "valsa brasileira", infelizmente suplantados por inúmeros passos para traz.

11 Por conta dessa divisão e por questões didáticas, passaremos a adotar o termo neodesenvolvimentismo a partir de agora.
} 
que estes optam por uma flexibilização maior da economia, menor participação do estado e se preocupam mais com a política monetária do que com o investimento público.

A linha seguida por Paulani (2017) é corroborada pela forma com que os neodesenvolvimentistas concebem o mercado, a saber, como o principal agente do desenvolvimento, como demonstra a segunda Tese sobre 0 neodesenvolvimentismo:

Markets are the major locus of this process, but the state has a strategic role in providing the appropriate institutional framework to support this structural process. This includes promoting a financial structure and financial institutions that channel domestic resources to the development of innovation in sectors that produce high rates of increase in domestic value added (...). (BRAZILIAN JOURNAL, 2012, p. 337)

Percebe-se que o estado ainda tem um papel importante de organização da economia, contudo, diferentemente do desenvolvimentismo clássico, o neodesenvolvimentismo concebe o mercado como principal ator do processo de desenvolvimento, cabe ao estado, apenas, dar a assistência necessária a esse ente enigmático.

Por outro caminho, Gonçalves (2012), aponta o período do Partido dos Trabalhadores (PT) no poder como um "nacional-desenvolvimentismo às Avessas", pois, segundo o autor, nega-se o núcleo do conceito: houve reprimarização das exportações, expansão do agronegócio; maior dependência tecnológica; maior concentração de capital; crescente dominação financeira, subordinação da política de desenvolvimento à política monetária, etc. Em consonância, Sampaio Jr. (2012) defende que na prática se apresentou um simulacro do desenvolvimento, pois confunde crescimento e modernização com desenvolvimento.

Fonseca (2015) mais preocupado com a formalização do conceito de desenvolvimentismo, divide a literatura sobre o assunto em duas esferas: a que se refere a um fenômeno teórico e a que considera as práticas históricas do "estado desenvolvimentista". Seguindo por essa via o autor constrói o seguinte conceito ${ }^{12}$ :

entende-se por desenvolvimentismo a política econômica formulada e/ou executada, de forma deliberada, por governos (nacionais ou subnacionais) para, através do crescimento da produção e da produtividade, sob a liderança do setor industrial, transformar a sociedade com vistas a alcançar fins desejáveis, destacadamente a superação de seus problemas econômicos e sociais, dentro dos marcos institucionais do

12 O conceito foi formado tendo como base o núcleo "duro" do desenvolvimentismo, já comentado acima, e comprovado por meio de comparação entre 34 governos latinoamericanos tidos pela literatura como desenvolvimentistas (uma forma de controle da pesquisa) (cf. FONSECA, 2015). 
sistema capitalista. (FONSECA, 2015, p.40)

Fonseca (2015) chama de "core" as características indispensáveis para caracterizar o desenvolvimentismo, a saber: industrialização, nacionalismo e intervenção estatal na economia. Entretanto, é possível, para o autor, que, devido a aspectos específicos de um momento histórico, haja o acréscimo ou a retirada de termos característicos para definir os projetos, esses termos são chamados "radiais". Como em capitalismo mercantil, monopolista, concorrencial, globalizado, de estado; democracia liberal, participativa, controlada; economia neoclássica, novo-clássica, pós-keynesiana.

O acréscimo de um conceito radial se dá para ampliar um conceito rígido com atributos desejáveis ou suprimir outros atributos. Sendo assim, apesar de concordar com a tese do "nacional-desenvolvimentismo às avessas", Fonseca (2015) entende a possibilidade de considerar esse período como um neodesenvolvimentismo, mesmo com o agronegócio no lugar da indústria.

O dissenso entre os pesquisadores sobre esse período permite-nos considerar que (1) devido a reprimarização das exportações brasileiras, a associação do termo "desenvolvimentismo" às práticas do governo petista se torna delicada; e (2), a associação deste projeto ao neoliberalismo também não faz sentido, uma vez que é na tentativa de afastamento desse projeto que se pauta o neodesenvolvimentismo em discussão.

A análise de Fonseca (2015), permite-nos considerar o neodesenvolvimentismo como uma atualização necessária para tornar o conceito mais abrangente e, assim, encaixar o agronegócio nessa nova proposta. Por conseguinte, podemos assumir o desenvolvimentismo simplesmente como a busca por superar o subdesenvolvimento e, portanto, assumir o agronegócio como a possibilidade que o contexto econômico permitiu para o sucesso, ou não, desse projeto. Nesse sentido, a ideia precursora do movimento chamado desenvolvimentismo, a superação do subdesenvolvimento, continua existindo e passa a ter mais validade do que 0 meio através do qual se busca esse objetivo.

\section{A QUESTÃO AMBIENTAL NO NEODESENVOLVIMENTISMO: UMA PRAGMÁTICA INERENTE AO INTERESSE ECONÔMICO}

A reedição do desenvolvimentismo clássico, reivindica para si a defesa do meio ambiente como característica desse pensamento, Pochmann (2013), por exemplo, identifica o desafio da consolidação de uma economia fundada em bases sustentáveis ambientalmente, o que, para ele, resulta necessariamente no papel central dos direitos sociais. Na mesma orientação, 
Mercadante (2010) levanta dois desafios importantes para se pensar em termos de desenvolvimento socioeconômico: o desafio da criação da sociedade do conhecimento, onde a superação da educação de baixa qualidade viabilizaria a inovação e pesquisas mais robustas; e, o desafio da sustentabilidade ambiental, isto é, da transição para a economia verde, que, garantirá o crescimento sustentado de longo prazo.

Contraditoriamente, o papel dos direitos sociais, defendido por Pochmann (2013), se apresenta no neodesenvolvimentismo como o fortalecimento do consumo popular com vista a dinamizar o mercado interno. Mercadante (2010), situa seu objeto de pesquisa da mesma forma ao afirmar que para participar do processo de distribuição de renda os indivíduos devem estar habilitados por títulos de propriedade. Claramente, ambos autores estabelecem que o marco principal das medidas do governo Lula foi a democratização da propriedade, por meio das medidas, citadas anteriormente, de distribuição direta de renda, ampliação de créditos e valorização do salário-mínimo.

Do ponto de vista desse pensamento a inclusão social está subordinada diretamente ao mercado de consumo, assim, o consumismo, além de estrutural, passa a representar uma responsabilidade moral do estado neodesenvolvimentista, exercendo papel semelhante à saúde e educação; no limite, desempenha papel prioritário, pois é ele que sustenta a economia.

Dada a reconhecida insustentabilidade ambiental dos atuais padrões de consumo, percebe-se de imediato que a defesa da inclusão social via consumo de massa, apresentada pelo neodesenvolvimentismo contrasta com a expectativa de uma sustentabilidade ambiental, pois a centralidade do consumo na organização da sociedade inviabiliza reflexões mais aprofundadas sobre as causas da degradação do meio ambiente.

Essa contradição entre o interesse no desenvolvimento econômico e a preservação socioambiental é acirrada quando se revela a tentativa de mascarar as injustiças sociais com discursos conciliadores, como o da reciclagem. Existe, um "cinismo da reciclagem", apontado por Layrargues ${ }^{13}$ (2002), que se dedica a proposição de uma educação ambiental comportamental, pautando a técnica da disposição do lixo domiciliar (coleta convencional $x$ coleta seletiva) e preterindo as reflexões sobre o estilo de produção e consumo da sociedade moderna.

\footnotetext{
$13 \mathrm{O}$ autor percebe que numa sociedade devotada à cultura do consumo a frugalidade é tida como um sacrifício ou uma privação, já que é a posse de bens materiais que garantem a felicidade. Na verdade, um estilo de vida frugal pode, inclusive, acarretar sérios danos à economia. Por isso a reciclagem se torna a melhor opção, pois ela não ameaça o sistema dominante, já que não questiona o consumismo. Recicla-se para não reduzir o consumo. (cf. LAYRARGUES, 2002)
} 
Dentro do discurso ecológico alternativo, Layrargues (2002) afirma haver uma lógica sequencial no que diz respeito à pedagogia dos 3R's, onde a redução do consumo deveria ser priorizada sobre a reutilização e a reciclagem; a reutilização seguiria a redução ou estaria no mesmo patamar; e, a reciclagem seria a última alternativa. Essa sequência, entretanto, foi alterada pela pedagogia ambiental hegemônica, na qual a questão do lixo é concebida como um problema de ordem técnica, e não cultural, o que desloca a sequência prioritária da pedagogia dos 3R's. Assim, a reciclagem passa a representar melhor alternativa do que a redução do consumo e o reaproveitamento.

A opção pela reciclagem é uma resposta evidente em favor da manutenção da lógica do consumo, pois transporta o problema para o desperdício e minimiza a necessidade de mudanças maiores. Segundo Layrargues (2002), a proposta de redução do consumo é tão subversiva, numa sociedade que trata a posse de bens materiais como o caminho para a felicidade, que no início dos anos 90 o Wall Street Journal chegou a especular que esse fenômeno poderia acarretar sérios danos à economia.

Por outro lado, a defesa da inovação e de pesquisas mais robustas associada à transição para uma economia verde, está interessada na possibilidade de sair na frente do processo de elaboração de produtos "ecologicamente corretos". Esse aspecto fica claro na fala de Mercadante (2010, p. 393):

O país reúne condições extremamente favoráveis para se colocar na vanguarda da conciliação entre o equilíbrio ambiental e o direito ao desenvolvimento. Temos matriz energética relativamente limpa e uma das maiores biodiversidades do planeta. Estamos à frente no uso de algumas energias renováveis e temos condições de estimular o uso mundial de biocombustíveis, sem prejudicar a produção de alimentos e a preservação dos biomas.

Deduz-se do trecho acima, que o caminho da sustentabilidade ambiental é uma oportunidade econômica que o Brasil não pode deixar de aproveitar, já que reúne vantagens territoriais quando comparado a outros países. E, sobretudo, "porque a economia verde também possui enorme potencial para gerar bons rendimentos e empregos de qualidade para as populações de baixa renda" (MERCADANTE, 2010, p. 397).

Novamente a problemática ambiental aparece nas proposições dos neodesenvolvimentistas associada ao desenvolvimento econômico, entretanto domesticada à lógica do crescimento, pois, "a sustentabilidade ambiental só poderá ser resolvida mediante avanços tecnologicamente inovadores e economicamente viáveis" (MERCADANTE, 2010). Se levarmos em consideração o modelo que temos visto de desenvolvimento, é economicamente viável todo investimento que não prejudica o lucro dos 
capitalistas.

Outro exemplo de contradição se refere à legislação ambiental, onde se nota a lógica de isolamento e proteção de reservas ambientais. A premissa desse tipo de política se baseia numa ruptura da "cidade" e do "campo" e, nessa separação, garantem-se lugares para se preservar e, em contraposição, outros lugares para poluir. "Nas cidades, por exemplo, não se reivindicam rios limpos, no máximo se garante uma Unidade de Conservação (UC) aos mananciais em que se capta a água potável" (BOMFIM, 2013, p. 71).

$\mathrm{Na}$ disputa de interesses a pauta ambiental aparece sempre fragilizada em comparação com a pauta desenvolvimentista. Em 2014, o Ministro Chefe da Secretaria-Geral da presidenta Dilma Rousseff, Gilberto Carvalho, concedeu para a BBC Brasil. Nessa ocasião, o ministro apontou que o governo não avançou no reconhecimento de terras indígenas por "falta de competência e clareza"; contudo, quando perguntado sobre a repressão dos protestos contra a usina de Belo Monte afirmou que:

quando você mantém um diálogo permanente - e instalamos lá uma casa de governo para dialogar - e se apela para ocupação de uma obra que tem interesse nacional, é dever do Estado enviar todos os esforços para que a obra retome o ritmo. (CARVALHO, 2014, p.1)

A fala de Gilberto Carvalho evidencia o quanto o "interesse nacional", presente no discurso neodesenvolvimentista, subordina as pautas que destoam desse projeto de desenvolvimento econômico, mesmo que essas pautas sejam defendidas na teoria pelo governo.

Outro ponto importante, que já vimos anteriormente, é que, no neodesenvolvimentismo, assim como a intervenção estatal deixa de ser direta, como com a criação de empresas públicas, e se volta ao fortalecimento do consumo de massas, a industrialização perde espaço como principal agente do desenvolvimento econômico para a agropecuária e para a mineração. Mercadante (2010) aponta que isso ocorreu devido ao processo de recuperação da economia no período de 2003-2008, onde o complexo agroindustrial se apresentou como o principal gerador de superávits da balança comercial brasileira. As exportações agrícolas aumentaram de US\$ 24,8 bilhões, em 2002, para US\$ 71,8 bilhões, em 2008, enquanto as importações aumentaram de US\$ 4,4 bilhões para US\$11,8 bilhões.

A estrutura do neodesenvolvimentismo se aproxima ${ }^{14}$ do que Gudynas

\footnotetext{
14 Se "aproxima", não é a mesma coisa, uma vez que o neoextrativismo se apresenta como uma descrição de um processo, enquanto o Neodesenvolvimentismo é um modelo propositivo de desenvolvimento, não só interpreta como aponta um caminho.
} 
(2012) chama de "Neoextrativismo"15, manifestado em diversos governos latino-americanos. Esse neoextrativismo degradador se apropria da natureza e exporta matérias primas em natura, ou pouco processadas, por conta disso concebe o território de forma produtivista e pragmática, desvalorizando outras lógicas de ocupação do território, que podem se tornar "áreas de sacrifícios".

Por conta disso, os conflitos socioambientais se voltam para questões relacionadas com a terra, como a expansão territorial da agropecuária e da mineração e a gestão dos recursos hídricos. Daí o crescimento do debate sobre a demarcação de terras indígenas, concentração fundiária, a poluição dos aquíferos, a ocupação do cerrado, o uso de agrotóxicos, entre outros.

Investigar a questão ambiental no contexto neodesenvolvimentista exige a compreensão dos problemas rurais que se multiplicam diuturnamente com a escolha dessa alternativa. Um exemplo é a contínua diminuição da população ocupada com agricultura, que caiu em 4,3 milhões de trabalhadores entre 2004 e 2015 (SILVEIRA, 2017).

Em suma, no projeto neodesenvolvimentista, a sustentabilidade aparece como um possível apêndice da questão econômica, podendo ser viabilizada quando for rentável e negligenciada quando não for, isso fica evidente nos trabalhos de Mercadante (2010), Pochmann (2013) e BresserPereira (2013). Na verdade, se propõe "um desenvolvimentismo que nas suas fases iniciais é apenas econômico, mas depois, graças à luta dos trabalhadores ou dos pobres, tende a ser democrático e social, e mais tarde ainda, ambiental (BRESSER-PEREIRA, 2013, p.23).

É emblemático que um projeto progressista, interessado na participação popular, na distribuição de renda e na defesa do meio ambiente, coloque o interesse econômico acima dos interesses dos trabalhadores. Isso confirma nossa suspeita de que mesmo a proposta mais avançada de desenvolvimento sustentável esbarra num limite quando decide assumir a lógica capitalista.

\section{CONSIDERAÇÕES FINAIS}

A proposta deste artigo foi investigar como é tratada a questão ambiental no contexto neodesenvolvimentista, vivido principalmente nos anos de governo do Partido dos Trabalhadores, e, com isso, proporcionar uma

\footnotetext{
15 Assim o autor define o neoextrativismo: "o neoextractivismo se caracteriza por mantener, e incluso profundizar, la extracción minera y petrolera, sea por un aumento en los rubros clásicos o por la incorporación de nuevos recursos (por ejemplo, países tradicionalmente no mineros que intentan la megaminería como Uruguay, o países mineros que buscan nuevos rubros como el litio en el caso de Bolivia). A su vez, el modo extractivista de organizar la producción se expande a otros sectores, en particular los monocultivos de exportación."
} 
leitura diligente desse período para a construção de uma Educação Ambiental Crítica.

$\mathrm{Na}$ busca de cumprir tal tarefa percebemos que as características definidoras do desenvolvimentismo são relativizadas ou reorientadas no neodesenvolvimentismo. Assim, o nacionalismo se torna um concílio de classes; a intervenção estatal é concebida de modo a garantir a melhor alocação dos entes privados; e, a industrialização perde força como alavanca para o desenvolvimento. De toda forma, por mais que os três parâmetros desenvolvimentistas tenham sido adaptados para o contexto políticoeconômico atual, o objetivo principal permanece sendo o mesmo: o desenvolvimento econômico para a superação do subdesenvolvimento.

Por conseguinte, novas características são incluídas nessa formulação, como por exemplo a pauta ambiental, que aparece nos discursos dos teóricos do neodesenvolvimentismo e em elaborações de leis desse período como as Unidades de Conservação. Constatamos, entretanto, que o interesse na questão ambiental se trata na verdade de uma possibilidade em se adiantar na promoção de uma economia "verde", visto que o Brasil tem as condições naturais para isso.

Essa visão pragmática equipara, na teoria, a ambição econômica aos interesses ambientais e, na prática, sempre que há algum tipo de impasse entre os dois interesses o desenvolvimento econômico se sobrepõe às necessidades do meio ambiente.

Esse percurso foi importante fazer porque precisávamos compreender até que ponto é possível ir com a Educação Ambiental Crítica dentro dessa proposta ainda capitalista de neodesenvolvimentismo. E conseguimos enxergar que há um teto importante, porque embora haja uma reconsideração da questão ambiental nesse "novo" modelo de desenvolvimento, não se deve infringir as determinações da economia ortodoxa, indicar outros limites ou propor ação que afete os negócios. Uma EA-crítica, por exemplo, que problematize o consumismo ou que questione o processo de reprimarização imposta pelo agronegócio não é bem acolhida. Essa conclusão foi importante obter.

Vale reiterar que tratamos de um período histórico (recente) da história do Brasil, que nos ofereceu essas importantes reflexões. Não obstante, em se tratando de capitalismo, não há situação desfavorável aos trabalhadores (e à questão ambiental) que não possa piorar (e piorar muito), principalmente quando os setores hegemônicos do capital querem retomar mais espaços. Porque depois do (curto) período da proposta neodesenvolvimentista petista, os primeiros anos do governo Bolsonaro trouxeram um retrocesso sem precedentes até mesmo para os parâmetros do capitalismo. Nesse momento, não se viu apenas o avanço das fronteiras agrícolas pelo agronegócio, mas uma expansão desenfreada (excessivamente ilegal) por reservas indígenas e 
territórios quilombolas, por terras da União, por Unidades de Conservação. Viu-se também incentivo ao extrativismo e mineração ilegais, inépcia em relação às queimadas tanto na Amazônia quanto no Pantanal. Viu-se um Ministério do Meio Ambiente aliado a grandes fazendeiros inescrupulosos, um Ministério sem qualquer política de ação, sem qualquer proposta sob qualquer aspecto (fosse mais ou menos progressista) para a questão ambiental. Sem dúvida, um período nefasto para a classe trabalhadora e para o meio ambiente.

Dessa forma, uma Educação Ambiental que se pretende Crítica precisará sempre ler também a conjuntura, mas em todas as situações pode considerar dois elementos que lhe serão estruturais: o pressuposto do conflito e o lado que precisa estar - dos oprimidos, dos trabalhadores e trabalhadoras que sofrem a exploração e veem seu ambiente ser degradado por uma classe minoritária dominante.

\section{REFERÊNCIAS}

BASTOS, P. P. Z. A economia política do novo-desenvolvimentismo e do social desenvolvimentismo. Economia e Sociedade, Campinas, v. 21, n. Especial, p. 779-810, dez. 2012.

BOFF, Leonardo; Sustentabilidade: o que é: o que não é. 1. Ed. Petrópolis, RJ: Vozes, 2012.

BOMFIM, A. M. O (Sub) Desenvolvimento (In)Sustentável: A Questão Ambiental nos países periféricos latino-americanos. In: Trabalho Necessário, Rio de Janeiro, ano 8, n. 10. Rio de Janeiro, UFF, 2010.

- Educação Ambiental (EA) para além do capital: Estudos e apontamentos para a EA sob a perspectiva do trabalho. Trabalho Necessário. Ed. Especial. ano 9, p. 1-20, 2011.ISSN: 1808 - 799X

A Questão Ambiental Diante do Paradoxo de Lula; Ampliando a reflexão-ação do Educador ambiental. In: ROÇAS, Giselle; ANJOS, Maylta Brandão dos. Reflexões Sobre a Prática e a Teoria da Educação Ambiental. Editora Publit, Rio de Janeiro, RJ. 2014.

Que fazer diante da Legislação Ambiental e Outros Textos Ambientais?: Alguns apontamentos aos Educadores. Revista Brasileira de Pesquisa em Educação em Ciências, v. 13, n. 2, p. 067-083, 2013.

BRAZILIAN JOURNAL of Political Economy. Ten theses on new 
developmentalism. Brazilian Journal of Political Economy. vol. 32, $\mathrm{n}^{\circ} 2$ (127), pp. 336-339, April-June/2012 Disponível em: http://www.scielo.br/pdf/ rep/v32n2/v32n2a11.pdf. Acesso em 25 novembro de 2020.

BRESSER-PEREIRA, L. C. Do ISEB e da CEPAL à Teoria da Dependência. Intelectuais e Política no Brasil, p. 201-232, 2005.

. Empresários, O Governo do PT e o Desenvolvimentismo. Revista de Sociologia e Política, v. 21, n. 47, P. 21-29, 2013.

CARVALHO, G. Dilma deixou a desejar no diálogo com a sociedade, diz ministro. [entrevista concedida a] João Fellet. BBC Brasil, Brasília, 2014. Disponível em: http://www.bbc.com/portuguese/noticias/ 2014/11/141108_entrevista_gilberto_jf_fd. Acesso em: 24 nov. 2020.

CARVALHO, L. Valsa brasileira: do boom ao caos econômico. São Paulo: Todavia, 2018.

CHESNAIS, F.; SERFATI, C. "Ecologia” e condições físicas de reprodução social: alguns fios condutores marxistas. Crítica Marxista. $n^{\circ} 16$. São Paulo: Editora Boitempo, 2003.

DOWBOR, L. A Era do Capital Improdutivo: a nova arquitetura do poder, sob dominação financeira, sequestro da democracia e destruição do planeta. 2.ed. São Paulo: Autonomia Literária, 2017.

FONSECA, P. C. D. Gênese e precursores do desenvolvimentismo no Brasil. Revista Pesquisa \& Debate. São Paulo, Volume 15, n. 2 (26), pp. 225-256, 2004.

. Desenvolvimentismo: a construção do conceito. In: DATHEIN, R. Desenvolvimentismo: o conceito, as bases teóricas, as políticas. Porto Alegre: Ed. UFRGS, 2015.

FREIRE, P. Pedagogia do oprimido. 50. Ed. Rio de Janeiro, RJ: Paz e Terra, 2011.

GONÇALVES, R. Governo Lula e o Nacional-Desenvolvimentismo ás Avessas. Revista soc. Bras. Economia política, São Paulo, n 31, p. 5-30, fevereiro 2012.

GUDYNAS, E. Estado Compensador y Nuevos Extractivismos. Nueva Sociedad, n. 237.2012

GUIMARÃES, M. A formação de Educadores Ambientais. 8. Ed. Campinas, SP: Papirus, 2012.

HAFFNER, J. A. H. A Cepal e a Industrialização Brasileira (1950- 1961). 1. 
ed. Porto Alegre: EDPUCRS. 2002.

HARVEY, D. Condição Pós-Moderna: uma pesquisa sobre as origens da mudança cultural. 26.ed. São Paulo: Loyola, 2017.

LAYRARGUES, P. P. O Cinismo da Reciclagem: O significado ideológico da reciclagem da lata de alumínio e suas implicações para a educação ambiental. In: LOUREIRO, C. F. B.; LAYRARGUES, P. P.; CASTRO, R. S. Educação ambiental: repensando o espaço da cidadania. p. 179-219. São Paulo: Cortez. 2002.

LIMA, G. F. C. O discurso da sustentabilidade e suas implicações para a educação. Ambiente e Sociedade, Campinas, v. 6, n. 2, jul.-dez. 2003.

; LAYRARGUES, P. P. Mapeando as macro-tendências políticopedagógicas da educação ambiental contemporânea no Brasil. VI Encontro Pesquisa em Educação Ambiental. Ribeirão Preto, set. 2011.

LOWY, M. Crise ecológica, crise capitalista, crise de civilização: A alternativa ecossocialista. Caderno CRH, v. 26, n. 67, p. 79-86, 2013.

. Ecossocialismo e planejamento democrático Crítica Marxista, n. 28, p. 35-50, 2009.

A Alternativa Ecossocialista. In: Crise Hídrica em Debate/ Câmara Municipal do Rio de Janeiro. Comissão Especial sobre o Colapso Hídrico. Rio de Janeiro: Editora NPC, 2016. ISBN: 978-85-63004-22-2

MERCADANTE, A. As Bases do Novo Desenvolvimentismo no Brasil: Análise do Governo Lula (2003-2010). Tese de Doutorado apresentada ao Instituto de Economia da Universidade Estadual de Campinas UNICAMP, p. 356, 2010.

MÉSZÁROS, I. A educação para além do capital. 2. Ed. São Paulo, SP: Boi Tempo. 2008.

Para além do capital. Campinas/SP: Boitempo, 2002.

OLIVEIRA. T. S. A Dimensão Ambiental na Educação Neodesenvolvimentista: um percurso teórico até a sua materialização. Dissertação de Mestrado Acadêmico em Ensino de Ciências. Programa de Pós-graduação em Ensino de Ciências (Propec). Instituto Federal de Educação, Ciência e Tecnologia do Rio de Janeiro. 2019.

PAULANI, L. M. A inserção da economia brasileira no cenário mundial: uma reflexão sobre a situação atual à luz da história. Boletim de Economia e Política Internacional, Brasília: Ipea, v. 10, p. 89-102, 2012.

Vol. $02(2020)$ 
. A experiência brasileira entre 2003 e 2014: Neodesenvolvimentismo?

Cadernos do Desenvolvimento, v. 12, n. 20, p. 135-155, 2017.

POCHMANN, M. Desafios do desenvolvimento brasileiro. Educação \& Sociedade, v. 34, n. 124, p. 705-722, 2013.

PORTO-GONÇALVES, C. W. A Globalização da Natureza e a Natureza da Globalização. 5. ed. Rio de Janeiro: Civilização Brasileira, 2013.

PREBISCH, R. O Desenvolvimento Econômico da América Latina e Alguns de seus Problemas Principais. CEPAL, Boletin económico de América Latina, v. VII, p. 71-136, 1962.

SAMPAIO JR, P. A. Desenvolvimentismo e Neodesenvolvimentismo: Tragédia e Farsa. SERVIÇO SOCIAL E SOCIEDADE, SÃO PAULO, N. 112, P. 672-688, OUT./DEZ. 2012

SICSÚ, J.; PAULA, L. F.; MICHEL, R. POR QUE NOVODESENVOLVIMENTISMO? REVISTA DE ECONOMIA POLÍTICA, VOL. 27, N.4, P. 507-524, 2007.

SILVEIRA, F. G. O Trabalho Agrícola no Boom do Agronegócio e na Expansão das Políticas Para a Pequena Agricultura. in: Mercado de Trabalho: Conjuntura e Análise. n. 63, P. 27-38, 2017. 